\title{
Shear strength and retention models of a partially saturated riverbank silty soil
}

\author{
Mariagiovanna Moscariello ${ }^{1}$, Carmine Gerardo Gragnano, ${ }^{2,}$, Sabatino Cuomo ${ }^{1}$, Irene Rocchi ${ }^{3}$ and Guido Gottardi ${ }^{2}$ \\ ${ }^{1}$ Department of Civil Engineering, University of Salerno, Italy \\ ${ }^{2}$ Department of Civil, Chemical, Environmental and Materials Engineering, University of Bologna, Italy \\ ${ }^{3}$ Department of Civil Engineering, Technical University of Denmark, Denmark
}

\begin{abstract}
Soil mechanical behaviour is strictly related to its natural water content, which is primarily dependent on hydraulic boundary conditions. When soils are partially saturated, as frequently occur in river embankments, soil suction also turns into a fundamental variable worth of investigation and monitoring, both in laboratory and in the field, for a reliable interpretation of the related soil response to external actions. The case of earthen water retaining structures and their safety condition assessment towards local or global collapse mechanisms requires special attention for soil characterization and site measurement of unsaturated soil states. Moreover, strength and hydraulic models used for relevant stability analyses should be adequate for representing the site-specific behaviour of soil in terms of water content, pore water pressure and suction values, relying on the effective possibility to properly calibrate all required parameters. Nevertheless, these aspects typically receive only limited attention, especially in standard practice, leading to inaccurate estimates of flood hazard and related risk management. In this context, with the aim of comprehensively studying the strength and retention properties of a riverbank silty soil, a series of laboratory investigations - including oedometric and direct shear tests under suction-controlled conditions have been performed. Laboratory tests are here used as the main direct source of information to model unsaturated soil behaviour, monitoring different state variables under suction-controlled conditions. The results have been then interpreted using both literature and soil-specific mechanical and hydraulic models, to be possibly implemented in integrated methodologies for the stability assessment of river embankments.
\end{abstract}

\section{Introduction}

The application of unsaturated soil mechanics within geotechnical engineering practice has strong potentialities and implications for collapsible soils, earth structures, foundations and slopes. Significant headway to address these problems, establishing rational approaches in routine practice have been carried out in the last decades [1], [2]. Nevertheless, even if various research achievements evidence the benefit of considering unsaturated soil concepts and procedures in geotechnical design analyses (e.g. [3]), they are rarely used in standard practice. A good example of the current gap between research and practice is represented by earthen infrastructures, as river and road embankments, which are generally located above the groundwater level and typically in partially saturated conditions during their lifetime; despite this, their response to external actions (hydraulic and climatic boundaries variations) is generally determined neglecting the effect of negative pore-water pressures. This assumption may produce excessively prudential considerations on design geometry (cutting and slopes) or safety margins (riverbanks and earth dams), but also unrealistic predictions of relevant geotechnical performance. Effort, time and cost for parameters determination together with difficulties in the measurement and estimation of soil suction are often quoted as reasons for the limited use of unsaturated soil mechanics. Results from research activities and reference cases can certainly support the adoption of unsaturated soil concepts for the implementation of engineering works. In this context, an experimental study on the mechanical and hydraulic response of a river embankment has been carried out through site, laboratory and numerical investigations [4]-[7]. Shear strength and retention models for the filling material, a well compacted silty soil, have been determined from oedometric and direct shear tests, both performed under saturated and suction-controlled conditions. In this contribution, related results are presented and discussed, providing key information for the analysis of riverbank safety conditions towards slope instability, possibly occurring after cyclic high-water levels, with great importance and repercussions for flood risk management. 


\section{Case study}

\subsection{Experimental site}

An embankment section of river Secchia (North Italy) has been considered for the experimental study. The geometry is approximately $11 \mathrm{~m}$-high from the ground level, with $4.6 \mathrm{~m}$-wide crest, slope angles about $30^{\circ}$ and $25^{\circ}$ toward riverside and landward. The embankment section selected for the implementation of the monitoring system is placed approximately $15 \mathrm{~km}$ downstream to a section collapsed on January, 19th 2014, in direction of the Po River [8].

Various factors guided the selection: firstly, the accessibility of the crest and bank of the sector, which is generally not easily guaranteed in terms of service and facilities. Secondly, the zone nearby the selected section has been involved by an earlier monitoring system (2014) aiming at measuring soil water content and water pressure by means of ADR and piezometric measurements, respectively (Fig. 1). In addition, the neighbourhood of the selected sector has been previously involved in various operations aiming to improve the safety towards under seepage process; even if these operations did not directly involve the section designated for the experimental studies, they all contributed to provide a sufficient level of knowledge about riverbank and foundation soils properties, hydrological features for the embankment sector, which were used as preliminary information for the first hypothesis on the monitoring design.

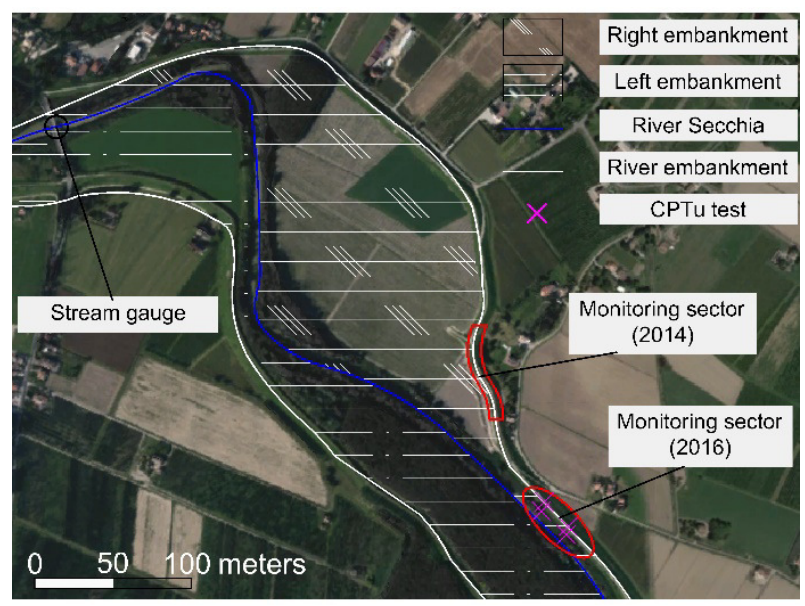

Fig. 1. Layout and details of the monitoring area.

A thoughtfully monitoring system has been there installed for obtaining time series of soil water content and pore-water pressure (both positive and negative), through direct (pressure transducer) and indirect measures (dielectric sensors) up to $8.0 \mathrm{~m}$-depth. Four CPTu tests, two from the top of the embankment and two from the river bank, have been performed to determine the geotechnical model of the section and to estimate the spatial variability of soil parameters with depth, between $15 \mathrm{~m}$ and $25 \mathrm{~m}$.
The site tests have been performed in a dry period (June, 2016) so that the embankment was highly unsaturated; due to this, care should be taken when using the measured cone resistance in empirical correlation as suction can affect significantly the interpretation [9]. As countermeasure to improve data analysis, the actual effective stress was corrected based on the negative pore pressure profile determined using hydrostatic suction profile above groundwater table (approximately located at the bottom of the embankment from CPTU test). Then, the friction angle of the embankment material have been determined using specific correlation for coarse- [10] and fine-grained layers [11], obtaining an average value of $31.4^{\circ}$ considering the results from the two CPTu tests executed from the embankment crest (CPTU1 and CPTU2) which results in terms of pore water pressure $(\mathrm{u})$ and normalized cone resistance $\left(\mathrm{q}_{\mathrm{t}}\right)$ are plotted in Figure 2.

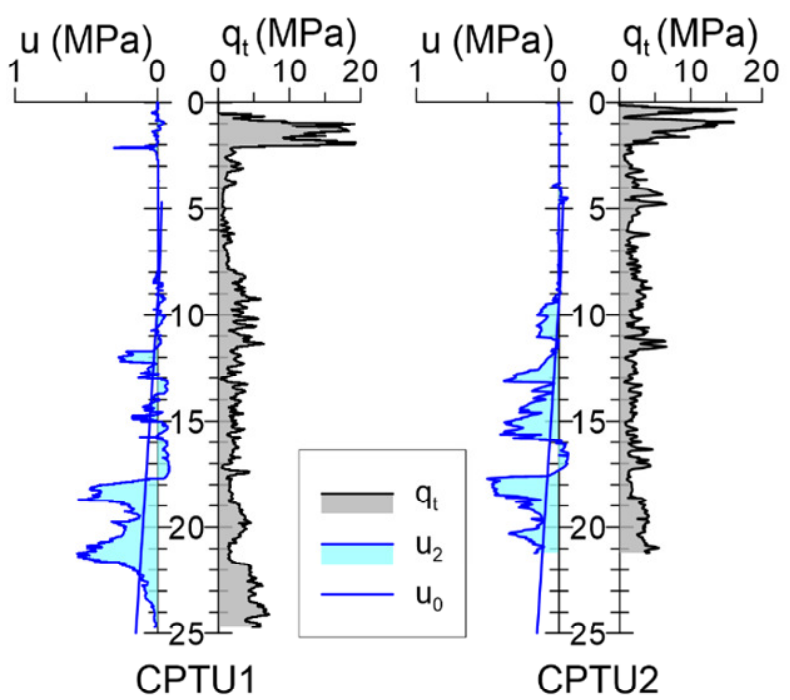

Fig. 2. CPTU test profiles from the embankment crest.

Nevertheless, this value should be still treated with caution as the correlations used have been obtained for saturated soils. Borehole cores were used to confirm soil characterization of the embankment soil layers gathered from site investigations. Generally, discrepancy was only found up $2 \mathrm{~m}$ depth, wherein suction can reach extremely high values, as it will be shown in the following. An accurate soil laboratory investigation in partially saturated investigation was then necessary for proper strength parameter estimation.

\subsection{Filling material characterization}

The material unit composing the embankment consists of a complex alternation of silt and sandy silt, with different thin sandy layers, with thickness of about 8 to $9 \mathrm{~m}$ from the crest level. Samples up to $7.5 \mathrm{~m}$ depth were here taken to assess geotechnical soil properties of this unit, where monitoring sensors have been principally installed. Physical properties determined from laboratory investigation are listed in Table 1, for different sampling depths $(d)$. Classification test conducted on disturbed 
samples evidenced a fine-grained soil percentage in this unit between 5 to $20 \%$ while silt accounts for 40 to $60 \%$ characterized by a Plasticity Index generally around $13 \%$ and by natural water content lower than the liquid limit, $w_{\mathrm{LL}}$. Values of the diameter corresponding to $10 \%$ and $50 \%$ finer in the grain size distribution, $\mathrm{D}_{10}$ and $\mathrm{D}_{50}$ respectively, the plastic limit, $\mathrm{W}_{\mathrm{PL}}$, specific gravity, $\mathrm{G}_{\mathrm{S}}$, and the uniformity and curvature coefficient for particle size distribution, $\mathrm{C}_{\mathrm{U}}$ and $\mathrm{C}_{\mathrm{C}}$, are listed in table 1 .

Grain size analysis evidences a large variation of both uniformity coefficient (between 9.3 to 132.5 ) and curvature coefficient (between 0.2 and 5.6), suggesting a significant, intrinsic heterogeneity of the filling material, confirming the CPTU-based interpretation, which is therefore typical for this kind of earth structures whose construction progress mainly relied on progressive compaction of site-available natural soils.

Riverbank retention and hydraulic properties have been preliminary studied in laboratory through a series of evaporation tests conducted on remoulded samples for various depths using different initial void ratio values ranging from 0.62 to 0.78 [4].

Then, an extensive experimental programme including suction-controlled oedometer and direct shear test has been carried out on intact specimens [5], [7]. Experimental setup, shear strength and retention models determined from results interpretation are hereafter presented and discussed.

Table 1. Physical properties of the embankment material.

\begin{tabular}{|c|c|c|c|c|c|c|c|}
\hline $\begin{array}{c}\mathrm{d} \\
(\mathrm{m})\end{array}$ & $\begin{array}{c}\mathrm{D}_{50} \\
(\mathrm{~mm})\end{array}$ & $\begin{array}{c}\mathrm{D}_{10} \\
(\mathrm{~mm})\end{array}$ & $\begin{array}{c}\mathrm{w}_{\mathrm{PL}} \\
(\%)\end{array}$ & $\begin{array}{c}\mathrm{w}_{\mathrm{LL}} \\
(\%)\end{array}$ & $\begin{array}{c}\mathrm{G}_{\mathrm{S}} \\
(-)\end{array}$ & $\begin{array}{c}\mathrm{C}_{\mathrm{U}} \\
(-)\end{array}$ & $\begin{array}{c}\mathrm{C}_{\mathrm{C}} \\
(-)\end{array}$ \\
\hline 1.8 & 0.032 & 0.000 & 16.70 & 29.43 & 2.63 & 132.5 & 2.4 \\
\hline 2.8 & 0.021 & 0.002 & 19.31 & 29.90 & 2.71 & 23.3 & 0.2 \\
\hline 3.8 & 0.045 & 0.008 & 18.11 & 30.03 & 2.57 & 9.3 & 0.2 \\
\hline 3.8 & 0.073 & 0.004 & 21.38 & 36.39 & 2.71 & 20.5 & 5.6 \\
\hline 3.8 & 0.121 & 0.013 & - & - & 2.67 & 11.8 & 2.2 \\
\hline 4.6 & 0.079 & 0.002 & 18.71 & 34.70 & 2.60 & 56.7 & 5.6 \\
\hline 5.1 & 0.125 & 0.009 & - & - & - & 17.9 & 3.4 \\
\hline 6.3 & 0.039 & 0.001 & - & - & 2.63 & 53.7 & 4.9 \\
\hline 6.9 & 0.087 & 0.005 & - & - & 2.65 & 23.7 & 5.2 \\
\hline
\end{tabular}

\subsection{Experimental methodology}

A series of 10 laboratory tests are hereafter presented as part of the laboratory investigations and the laboratory protocol and details are summarized in Table 2.

Specimens have been obtained from undisturbed sampling performed on site at depth ranging from $4.0 \mathrm{~m}$ to $7.5 \mathrm{~m}$; however, when collecting the material from sampler, some issues due to the grain size of material (which is principally a silty sand matrix, having limited fine grained intrusion), some disturbs occurred to void ratio, $\mathrm{e}_{0}$, as a possible relaxation of the soil structure; thus, the values of lab test may also be underestimated respect to those determined in situ, varying from 0.57 to
0.62 at the considered depths. However, these aspects do not significantly undermine the experimental results, only limited the variations in degree of saturation upon the stress path considered (i.e. wetting, drying and shearing) [5], [7].

Soil retention and strength properties were thus determined considering net stress state $\left(\sigma_{n}-u_{a}\right)$ typical for the central core of the riverbank, almost constant during the lifetime of the structure, ranging from 60 to $120 \mathrm{kPa}$ (approximately corresponding to $3.5 \mathrm{~m}$ to $7.0 \mathrm{~m}$ depth from the embankment crest). Variables of interest (soil water content variation, shear resistance) were so measured in laboratory-controlled condition, e.g. varying suction $\left(\mathrm{u}_{\mathrm{w}}-\mathrm{u}_{\mathrm{a}}\right)$ in the range $0-100 \mathrm{kPa}$.

Soil hydraulic behaviour has been determined performing both drying and wetting paths in suctioncontrolled oedometric apparatus (two UOE tests), with a net stress equal to $90 \mathrm{kPa}$ (approximately equivalent to $5.5 \mathrm{~m}$ depth from the embankment crest), while only wetting paths have been conducted in suction-controlled direct shear (five UDS tests) apparatus, with net normal stress ranging from 60 to $120 \mathrm{kPa}$ and at nil shear stress and horizontal displacement.

Soil strength model in saturated condition was also obtained from specific test still using the UDS apparatus but keeping suction value equal to zero (three DS tests), performed at vertical stress in the range 60 to $120 \mathrm{kPa}$, with a view to compare results gathered from unsaturated conditions.

Table 2. Laboratory tests and boundary conditions.

\begin{tabular}{|c|c|c|c|c|}
\hline $\begin{array}{c}\mathrm{d} \\
(\mathrm{m})\end{array}$ & $\begin{array}{c}\text { Test type } \\
\text { and ID }\end{array}$ & $\begin{array}{c}\mathrm{e}_{0} \\
(-)\end{array}$ & $\begin{array}{c}\sigma_{\mathrm{v}}-\mathrm{u}_{\mathrm{a}} \\
(\mathrm{kPa})\end{array}$ & $\begin{array}{c}\mathrm{u}_{\mathrm{w}}-\mathrm{u}_{\mathrm{a}} \\
(\mathrm{kPa})\end{array}$ \\
\hline 4.3 & DS01 & 0.732 & 60 & 0 \\
\hline 4.1 & DS02 & 0.913 & 90 & 0 \\
\hline 4.1 & DS03 & 0.669 & 120 & 0 \\
\hline 5.2 & UDS01 & 0.530 & 90 & 75 \\
\hline 5.3 & UDS02 & 0.679 & 90 & 50 \\
\hline 5.5 & UDS03 & 0.508 & 90 & 60 \\
\hline 7.1 & UDS04 & 0.852 & 120 & 50 \\
\hline 7.4 & UDS05 & 0.767 & 60 & 50 \\
\hline 5.1 & UOE01 & 0.859 & 90 & $0-100$ \\
\hline 5.4 & UOE02 & 0.608 & 90 & $0-100$ \\
\hline
\end{tabular}

\section{Soil retention models}

SWRC (Soil Water Retention Curve) has a principal role in describing both soil mechanical and hydraulic behaviour in partially saturated conditions. For this, for a comprehensive description of strength and retention models data from wetting and drying paths have been plotted on the $S_{\mathrm{r}, \text { eff }}-\left(u_{\mathrm{w}}-u_{\mathrm{a}}\right)$ plane. The experimental data were interpolated using a simplified version of the van Genuchten [12] equation: 


$$
S_{r, e f f}=\left\{\frac{1}{1+[\alpha \cdot s]^{n}}\right\}^{m}
$$

where $m, n$, and $\alpha$ are soil constants and $S_{\mathrm{r}, \text { eff }}=(\theta$ $\left.\theta_{\mathrm{r}}\right) /\left(\theta_{\mathrm{s}}-\theta_{\mathrm{r}}\right)$ is the effective saturation, which is a function of saturated and residual volumetric water content $\left(\theta_{\mathrm{s}}\right.$ and $\theta_{\mathrm{r}}$ respectively). It was assumed that the degree of saturation tends to unit at zero suction and to zero when suction tends to infinity (i.e. the residual degree of saturation tends to zero). The experimental data for each net vertical stress were interpolated with Eq. 1 (Fig. 3). Moreover, the experimental results have been analysed using the relationship proposed by Gallipoli et al. [13] for the variation of degree of saturation in unsaturated soils, which incorporated the influence of changes in void ratio $(e)$. It was assumed that hydraulic hysteresis is negligible. The relationship is a modification of van Genuchten [15] equation, in which was incorporated the void ratio:

$$
S_{r, e f f}=\left\{\frac{1}{1+\left[\phi \cdot e^{\psi} \cdot s\right]^{n}}\right\}^{m}
$$

where $m, n, \phi$ and $\psi$ are soil constants. The SWRCs obtained at several void ratio value has been interpolated using the equation 2 and a single surface was identified (Fig. 4). Values of $m=0.27, n=1.31, \phi=0.81$ and $\psi=3.88$ were obtained and the surface well fitted the experimental data $\left(\mathrm{R}^{2}=0.89\right)$.

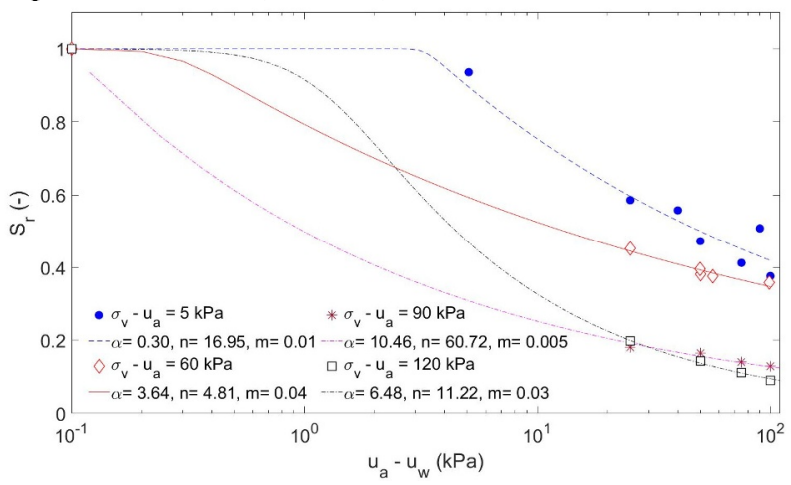

Fig. 3. Soil Water Retention Curves at different net vertical stress; for each curve $m, n$, and $\alpha$ are reported in the legend.

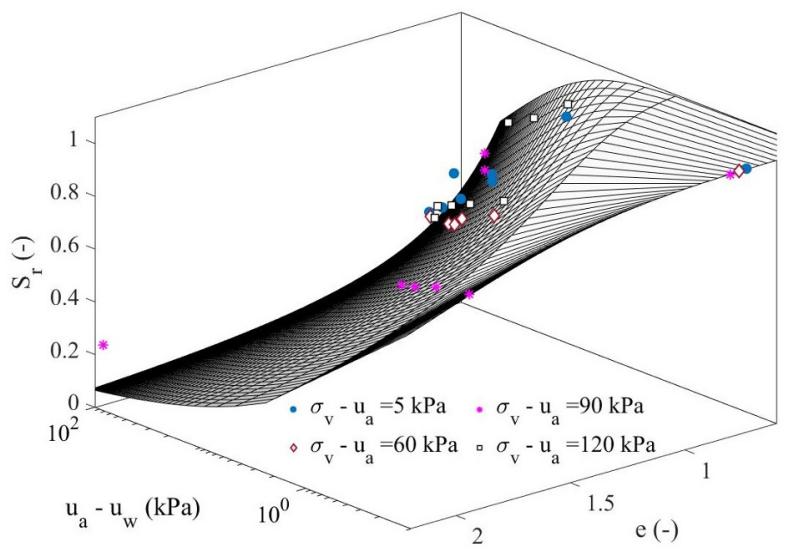

Fig. 4. Experimental Soil Water Retention surface in the $S_{\mathrm{r}, \mathrm{eff}}-$ $\left(u_{\mathrm{a}}-u_{\mathrm{w}}\right)-e$ space.

\section{Soil strength models}

A first interpretation of shear strength results can be obtained plotting tangential stress $(\tau)$ and net stress $\left(\sigma_{\mathrm{n}}-\right.$ $u_{\mathrm{a}}$ ) at failure conditions, (Fig. 5). Failure points have been interpolated using a simple Mohr-Coulomb criterion, differentiating among saturated (DS) tests and unsaturated (UDS) tests, but considering no cohesion for the strength model in saturated conditions, being a reasonable assumption for the type of soil. It can be seen that the increase of strength produced by partial saturated conditions is evident in a significant value of cohesion intercept $(14.8 \mathrm{kPa})$ and still a slight increment in the friction angle $\left(\Delta \varphi=1.4^{\circ}\right)$, having a certain impact in eventual safety and stability assessments. The results from UDS tests can also be interpreted considering as stress variables both the net stress tensor and the matrix suction. The effective stress is determined considering the generalization of Terzaghi's effective stress for unsaturated soils proposed by Bishop [14], given by:

$$
\sigma_{i j}^{\prime}=\sigma_{i j}-\delta_{i j} \cdot u_{a}+S_{r, e f f} \cdot \delta_{\mathrm{ij}} \cdot\left(u_{a}-u_{w}\right)
$$

where $\delta_{i j}$ is the Kronecker delta and $\mathrm{S}_{\mathrm{r}, \text { eff }}$ is the relative effective degree of saturation. Using this approach, results are then plotted in Figure 6 on the $\sigma^{\prime}-\tau$ plane. It can be here observed that the failure envelopes, both interpreted using the Mohr-Coulomb criterion, nearly overlaps at zero suction and $\Delta \varphi^{\prime}=0.1^{\circ}$. This still evidences the consistency of the experimental setup and reliability of results, which can provide an overall stating of the strength parameters usable for both saturated and unsaturated conditions. It is important to notice that, differently, friction angle value from CPTU test $\left(31.4^{\circ}\right)$ is significantly lower that the laboratory estimation. This finding is principally due to the fact that empirical correlation from test on saturated soil have been adopted for data interpretation, even if the actual effective stress was corrected based on the negative pore pressure profile as countermeasure, as stated before. This reveal a possible error when using CPTU test standard interpretation when dealing with unsaturated intermediate sediments, as silty soils, here quantified in around $\Delta \varphi^{\prime} \approx 6^{\circ}$.

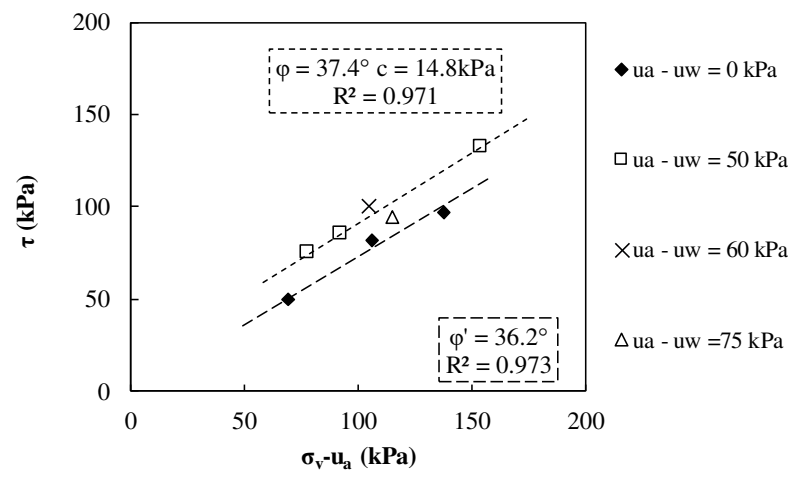

Fig. 5. Soil strength model using net vertical stress.

These tests should, so, be coupled with investigations on unsaturated soil state and behaviour, which may 
certainly improve the characterization of the geotechnical model.

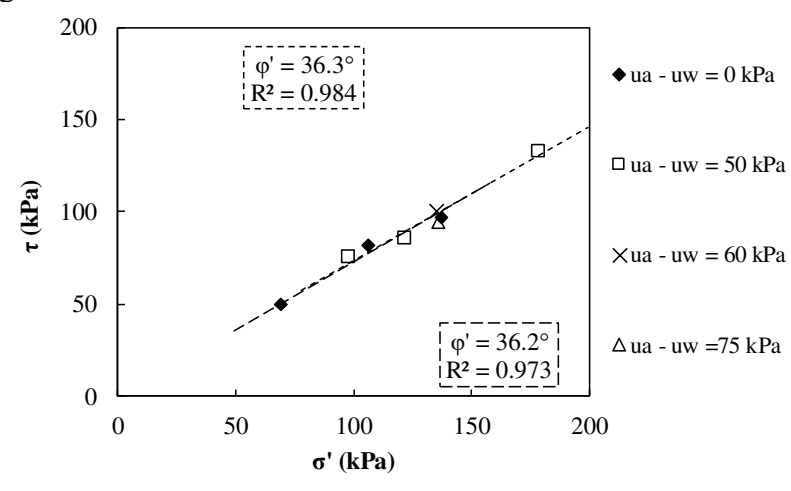

Fig. 6. Soil strength model using Bishop effective stress.

\section{Conclusions}

An extensive geotechnical investigation of a riverbank filling material has been performed in the framework of stability assessment of this type of linear infrastructures. Parallel to monitoring data, results from site and laboratory tests have been considered to determine soil behaviour in the partially saturated states representative of the study case. Retention properties have been determined using soil models also accounting for the influence of void ratio and net stress. It was observed a higher saturation degree when the void ratio is lowered and net stress is increased. The additional contribution to shear strength obtained from UDS with respect to DS tests is consistent with a partially saturated condition of the riverbank silty soil at the tested suction range; thus, in order to take into account a possible crucial improvement of strength properties, relevant information on the negative pore pressure distribution in the riverbank should be provided, as well as the soil strength response under both saturated and unsaturated conditions. Being the riverbank material subjected to frequent water content variations, though remaining largely unsaturated during its lifetime, it is crucial for a reliable assessment of safety conditions to carry out together with site monitoring - such specific laboratory investigation, no doubt affordable in the engineering practice, to be then coupled to suitable numerical simulations.

\section{Acknowledgements}

This work was carried out under the project INFRASAFE, funded within POR FESR 2014-2020 framework. Eng. Vito Foresta (Dept. of Civil Engineering, University of Salerno), is greatly acknowledged for his contribution to laboratory soil testing.

\section{References}

1. D. G. Fredlund, H. Rahardjo, and M. D. Fredlund, Unsaturated Soil Mechanics in Engineering Practice. Wiley \& Sons, Inc., Hoboken, New Jersey, 2012.
2. A. Tarantino and G. El Mountassir, "Making unsaturated soil mechanics accessible for engineers: Preliminary hydraulic-mechanical characterisation \& stability assessment," Eng. Geol., vol. 165, pp. 89-104, 2013.

3. D. G. Fredlund, "State of practice for use of the soilwater characteristic curve (SWCC) in geotechnical engineering," Can. Geotech. J., vol. 56, no. 8, pp. 1059-1069, 2019.

4. I. Rocchi et al., "A new technique for deep in situ measurements of soil water retention behaviour," Geotech. Res., vol. 5, no. 1, 2018.

5. C. G. Gragnano, G. Gottardi, M. Moscariello, S. Cuomo, and I. Rocchi, "Laboratory measurement of the mechanical and retention properties of a river embankment silty soil in partially saturated condition," in 7th International Conference on Unsaturated Soils, 2018.

6. C. G. Gragnano, I. Bertolini, I. Rocchi, and G. Gottardi, "On the Stability of a Fully Instrumented River Embankment Under Transient Conditions," in 7th Italian National Congress of Geotechnical Researchers, 2019.

7. C. G. Gragnano, M. Moscariello, S. Cuomo, G. Gottardi, and I. Rocchi, "Experimental study on a partially saturated soil in a river embankment," in XVII European Conference on Soil Mechanics and Geotechnical Engineering, 2019.

8. L. D'Alpaos, A. Brath, and V. Fioravante, "Relazione tecnico-scientifica sulle cause del collasso dell' argine del fiume Secchia avvenuto il giorno 19 gennaio 2014 presso la frazione San Matteo," http://Ambiente.Regione.EmiliaRomagna.it/geologia/notizie/notizie-2014/fiumeSecchia, 2014.

9. H. Yang and A. R. Russel, "Cone penetration tests in unsaturated silty sands," Can. Geotech. J., vol. 53, no. 3, pp. 431-444, 2016.

10. F. H. Kulhawy and P. W. Mayne, "Manual on Estimating Soil Properties for Foundation Design," 1990.

11. P. W. Mayne and R. G. Campanella, "Versatile site characterization by seismic piezocone," in 16th International Conference on Soil Mechanics and Geotechnical Engineering, 12-16 September, 2005, 2005, pp. 721-724.

12. M. T. van Genuchten, "A Closed-form Equation for Prediccting Hydraulic Conductivity of Unsaturated Soils," Soil Science Society of America Journal, vol. 44, no. 5. pp. 892-898, 1980.

13. D. Gallipoli, S. J. Wheeler, and M. Karstunen, "Modelling the variation of degree of saturation in a deformable unsaturated soil," Géotechnique, vol. 53, no. 1, pp. 105-112, 2003.

14. A. W. Bishop, "The principle of effective stress.," Tek. Ukebl., vol. 39, no. October, pp. 859-863, 1959. 